\title{
Patient satisfaction in neurological second opinions and tertiary referrals
}

\author{
D. Wijers $\cdot$ L. Wieske $\cdot$ M. D. I. Vergouwen • \\ E. Richard · J. Stam $\cdot$ E. M. A. Smets
}

Received: 12 April 2010/Accepted: 2 June 2010/Published online: 15 June 2010

(C) The Author(s) 2010. This article is published with open access at Springerlink.com

\begin{abstract}
Although the number of neurological second opinions (SOs) and tertiary referrals (TRs) is increasing, only little is known about expectations and patient satisfaction in this group of patients. Therefore, the purpose of this study was to explore expectations of patients who get a neurological SO or TR and to assess patient satisfaction in these groups of patients. All new patients attending an academic neurological day-care clinic in a 6-month period were investigated. Demographic characteristics, duration of symptoms, expectations and motivation, new diagnoses and treatment consequences were studied, and patient satisfaction with the previous physician and the day-care clinic physician was assessed. Three hundred consecutive patients (183 SOs and 117 TRs) were evaluated. SO patients were younger (47 years vs. 51 years), and their duration of symptoms was longer ( 24 vs. 13 months) than TR patients. Most patients expected a new diagnosis or treatment $(60 \%)$. SO patients were equally as satisfied with the day-care clinic consultation as TR patients (overall satisfaction using a VAS-score ranging 0-10: 7.4 vs. 7.5; $p=0.81$ ), and significantly less satisfied with the referring physician (overall satisfaction: 5.6 vs. $7.0 ; p<0.001$ ). SO patients, in particular, were more satisfied with the degree of information and emotional support provided by the
\end{abstract}

\footnotetext{
D. Wijers · L. Wieske - M. D. I. Vergouwen · E. Richard ( $₫)$. J. Stam Department of Neurology, Academic Medical Center, University of Amsterdam, Meibergdreef 9, 1105 AZ Amsterdam, The Netherlands

e-mail: e.richard@amc.uva.nl

E. M. A. Smets

Department of Medical Psychology,

Academic Medical Center, University of Amsterdam, Meibergdreef 9, 1105 AZ Amsterdam, The Netherlands
}

consulting neurologist as compared to the referring physician. Receiving a new diagnosis and/or treatment advice did not influence satisfaction. A day-care admission for neurological SO and TR leads to an increase of patient satisfaction, irrespective of making a new diagnosis or initiation of a new treatment.

Keywords Second opinion - Tertiary referral .

Satisfaction · Clinical neurology ·

Patient satisfaction questionnaire

\section{Introduction}

The number of second opinions (SOs) and tertiary referrals (TRs) has increased substantially in the last two decades to approximately $20 \%$ of all outpatient consultations $[1,2]$. SO are consultations initiated by a patient, mostly in accordance with their general practitioner, for a medical condition for which the patient already consulted a specialist. TR are initiated by a specialist because of lack of specific expertise or because of doubts about the diagnosis or treatment.

Information on patients' expectation and satisfaction with SOs and TRs in neurology is scarce. Available studies often focused on subgroups of neurological patients, such as patients with headache, and not on the entire spectrum of patients representative for regular neurological care [3-5].

The purpose of this study was to explore expectations of patients who seek a SO or TR in neurology and their satisfaction with a day-care admission for such a consultation. We assessed patients' satisfaction with the medical consultation that preceded the referral, and compared this with their satisfaction with the (subsequent) SO or TR consultation. Finally, we investigated differences in satisfaction 
between SOs and TRs, and studied predictors of patient satisfaction. Insight into these factors will help physicians understanding the motivation of their patients to ask for a SO, and this knowledge can be used to anticipate patients' expectations and could help preventing unnecessary further consultations.

\section{Methods}

All patients who attended the neurological day-care clinic of the Academic Medical Centre from February 2006 until August 2006 for SOs and TRs were included. There were no exclusion criteria. The organization of the day-care admission and the patient characteristics have been described previously [6]. In short, the day-care clinic provides tailored care for patients referred for a neurological SO or TR. Consultations are prepared by reviewing documents from referring physicians and planning of all necessary ancillary investigations. On the day of consultation patients are admitted for one day to provide sufficient time for history taking, neurological examination and differential diagnostic consideration. By planning ancillary investigations and subspecialist consultations on the same day, the goal is to have a (revised) diagnosis and/or treatment plan at the end of the consultation.

\section{Questionnaires}

Patients were asked to fill out two questionnaires: one in the waiting area prior to the consultation (pre-consultation questionnaire), and one afterwards on the same day (postconsultation questionnaire), before leaving the hospital. Post-consultation questionnaires which were not completed were sent to the patient's home address with a return envelope. If the post-consultation questionnaire was not returned at the end of the study period, multiple attempts were made to contact the patient by telephone. In case the patient had not responded after these attempts, the questionnaire was considered missing.

The pre-consultation questionnaire contained questions about patient characteristics including age, sex, educational level, number of doctors consulted, and duration of symptoms. Patients were asked about their expectations using a multiple choice response format constructed for this study specifically, including: (1) explanation about a diagnosis or treatment, (2) confirmation of a diagnosis or treatment, (3) getting a new diagnosis or treatment, or (4) other, in free text format. Only one answer was allowed. Furthermore, patients were asked to what extent they thought their expectations would be fulfilled.

Also, patients were asked to rate their satisfaction with the referring physician. Satisfaction was assessed using a patient satisfaction questionnaire, originally developed to measure satisfaction in hospitalized oncology patients [7]. It is a direct measure of the process of the consultation, seeking the patients' perspective of what occurred rather than the facts. The Dutch version of the instrument has since then been used in various outpatient settings, showing satisfactory reliability and validity, as indicated by internal consistencies of 0.90 and associations in the direction hypothesized [8-10]. The instrument consists of five questions that assess patients' satisfaction on a visual analogue scale (VAS) for each of the following items: (1) own involvement in the conversation, (2) physician's information giving, (3) own involvement in decision making, (4) physicians' emotional support, and (5) general satisfaction. Scores were summated and a mean overall satisfaction score was calculated, with a higher score indicating greater satisfaction (scores from 0 to 10). Internal consistency (Cronbach's alpha) in the present study was 0.90 .

The post-consultation questionnaire assessed satisfaction with the day-care clinic physician directly after the consultation using the same satisfaction questionnaire. Patients were also asked if they had the desire to independently seek an additional opinion from another physician in the future (yes/no).

Day-care physicians filled out a doctor-questionnaire directly after the consultation assessing whether or not a new diagnosis was made or a new treatment was advised.

\section{Statistical analysis}

Categorical variables were analyzed using the $\chi^{2}$ test, and differences between median values were tested with the Mood's median test for non-parametric data. Mean values are presented with range and standard deviation (SD), median values with range and interquartile range (IQR). Differences in satisfaction between the referring physician and the day-care clinic neurologist were analyzed with the paired samples $t$ test and are presented with a 95\% confidence interval (CI). To study explanatory variables for satisfaction, multiple linear regression was used. A blockwise entry was chosen to control for expected confounders. Block one contained demographic variables (i.e., age, gender, education), block two contained medical history variables (i.e., number of physicians previously consulted, symptom duration, satisfaction with previous physician), while block three assessed the referral type (SO or TR) as an explanatory variable. The model is provided with a total $R^{2}$ (explained variance) to describe the power of the prediction model as well as subsequent $R^{2}$ for each step. Differences were considered significant when $p \leq 0.05$. Data were analyzed with SPSS version 15.0 (SPSS, Chicago, IL). 


\section{Results}

A total of 300 patients visited the day-care clinic during the study period. 294 pre-consultation questionnaires (98\%), 287 post-consultation questionnaires (96\%), and 297 doctor questionnaires $(99 \%)$ were completed.

Baseline characteristics

Baseline characteristics and final diagnoses are listed in Table 1. SO patients were younger than TR patients (mean $\pm \mathrm{SD} 47 \pm 14$ vs. $51 \pm 15$ years, respectively; $p=0.01)$. SO patients had a longer duration of symptoms than TR patients (mean \pm SD $24 \pm 40$ vs. $13 \pm$ 28 months, respectively; $p=0.04$ ). The mean number of consulted physicians prior to the day-care admission was three (range 1-16). Educational level of patients in both groups was similar to the Dutch population (data not shown).

\section{Patients' expectations}

Patients' expectations are listed in Table 2. Most patients expected a new diagnosis or treatment $(60 \%)$ or explanation about a diagnosis or treatment (26\%). Expectations, and the degree to which patients anticipated that these expectations would be fulfilled, were similar among SO and TR patients.

\section{Satisfaction}

Satisfaction with the referring physician and day-care neurologist is shown in Fig 1. SO patients were equally satisfied with the day-care clinic neurologist as TR patients on all satisfaction items (overall satisfaction 7.4 vs. $7.5 ; p=0.81$ ). Both SO and TR patients gave higher scores on all items when comparing the day-care clinic physician with the referring physician, except for the general satisfaction in the TR group (mean difference $0.47 ; p=0.093$ ). The increase in overall satisfaction was significantly greater for SO than for TR patients [mean overall increase SO: 1.9 (95\% CI $1.3-2.5)$ vs. mean overall increase TR: 0.5 (95\% CI -0.1 to
$1.0) ; p<0.01]$. SO patients scored the largest increase in satisfaction on information (satisfaction item 2) and emotional support (satisfaction item 4) (mean increase of satisfaction item 2, 2.7 and mean increase of satisfaction item 4, 2.6 vs. mean overall increase 1.9$)$. In total 183 patients (62\%) received a new diagnosis and/or treatment advice after daycare consultation. Overall satisfaction for patients who received a new diagnosis and/or treatment advice was 7.6, while overall satisfaction for patients who did not receive a new diagnosis and/or treatment proposal was 7.5 $(p=0.645)$. SO patients who received a new diagnosis and/ or treatment advice were equally as satisfied with the consultation as SO patients who did not receive a new diagnosis and/or treatment advice (mean satisfaction 7.5 for $102 \mathrm{SO}$ patients who received a new diagnosis and/or treatment advice vs. 7.4 for $80 \mathrm{SO}$ patients who had not received a new diagnosis and/or treatment advice; $p=0.846$ ). TR patients who received a new diagnosis and/or treatment advice showed equal satisfaction when compared to TR patients who had not received a new diagnosis and/or treatment advice (mean satisfaction 7.5 for 81 TR patients who received a new diagnosis and/or treatment advice vs. 8.1 for 34 TR patients who had not received a new diagnosis and/or treatment advice; $p=0.078$ ).

After admission to the day-care clinic, 26 patients (9\%) expressed the intention to seek an additional opinion. Satisfaction of these patients with the day-care clinic physician was significantly lower on all items (overall satisfaction 4.5 vs. $7.9 ; p<0.001)$. These patients were also significantly less satisfied with the referring physician $(p<0.001)$. Twenty-one patients did not complete the questionnaire immediately after consultation and were contacted by telephone. These patients were significantly less satisfied with the day-care clinic consultant $(p<0.001)$.

\section{Explanatory variables for satisfaction}

Table 3 shows the results of the linear regression of variables associated with satisfaction. When controlling for demographic and medical history variables, a SO as referral type explained a higher satisfaction after consultation

Table 1 Baseline characteristics of included patients

\begin{tabular}{lllll}
\hline & $\begin{array}{l}\text { Total } \\
n=300\end{array}$ & $\begin{array}{l}\text { Second opinion } \\
(\mathrm{SO}) n=183\end{array}$ & $\begin{array}{l}\text { Tertiary referral } \\
(\mathrm{TR}) n=117\end{array}$ & $\begin{array}{l}\text { Difference } \\
\text { SO }- \text { TR }(p)\end{array}$ \\
\hline Age in years [mean \pm SD (range)] & $49 \pm 15(16-86)$ & $47 \pm 14(18-84)$ & $51 \pm 15(16-86)$ & 0.01 \\
$\begin{array}{l}\text { Number of males (\%) } \\
\begin{array}{l}\text { Number of previously consulted doctors } \\
\text { median } \pm \text { IQR (range) }\end{array}\end{array}$ & $140(47 \%)$ & $82(45 \%)$ & $58(50 \%)$ & 0.48 \\
$\begin{array}{l}\text { Duration of symptoms in months } \\
\text { median } \pm \text { IQR (range) }\end{array}$ & $18 \pm 34(1-456)$ & $24 \pm 40(1-456)$ & $13 \pm 28(1-420)$ & 0.19 \\
\end{tabular}

$S O$ second opinion, $T R$ tertiary referral, $S D$ standard deviation, $I Q R$ interquartile range 
Table 2 Patients' expectations

\begin{tabular}{|c|c|c|c|c|}
\hline & $\begin{array}{l}\text { Total } \\
n=285^{\mathrm{a}}\end{array}$ & $\begin{array}{l}\text { Second opinion } \\
\text { (SO) } n=174\end{array}$ & $\begin{array}{l}\text { Tertiary referral } \\
\text { (TR) } n=111\end{array}$ & $\begin{array}{l}\text { Difference } \\
\mathrm{SO}-\mathrm{TR}(p)\end{array}$ \\
\hline Expectations (\%) & & & & 0.87 \\
\hline Explanation & $26 \%$ & $28 \%$ & $23 \%$ & \\
\hline Confirmation of diagnosis or treatment & $7 \%$ & $6 \%$ & $10 \%$ & \\
\hline New diagnosis/treatment & $60 \%$ & $59 \%$ & $62 \%$ & \\
\hline Other $^{\mathrm{b}}$ & $7 \%$ & $8 \%$ & $5 \%$ & \\
\hline $\begin{array}{l}\text { Anticipation that expectations will be } \\
\text { fulfilled (mean VAS } \pm \mathrm{SD} \text { ) }\end{array}$ & $6.5( \pm 2.3)$ & $6.5( \pm 2.4)$ & $6.6( \pm 2.1)$ & 0.87 \\
\hline
\end{tabular}

$S O$ second opinion, $T R$ tertiary referral, $V A S$ visual analogue scale, $S D$ standard deviation

${ }^{\text {a }}$ Missing data from nine patients: incomplete questionnaires

b Other, e.g. 'getting rid of the pain'

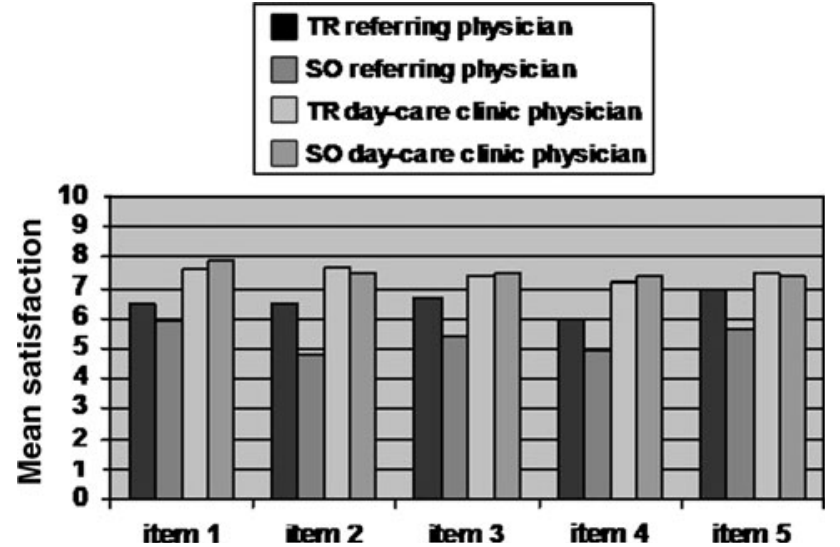

Fig. 1 Mean satisfaction per item of the satisfaction questionnaire. Mean satisfaction as measured on the visual analogue scale (ranging from 0 'not at all' to 10 'completely') for all satisfaction items. Satisfaction item: (1) own involvement in the conversation, (2) physician's information giving, (3) own involvement in decision making, (4) physicians' emotional support, (5) general satisfaction. $S O$ second opinion patients, $T R$ tertiary referrals

$(p=0.019)$. Overall the model explained $14.2 \%$ of all variance, with every step showing a significant improvement in predictive power. Interestingly, the number of physicians previously consulted was not associated with satisfaction ( $p=0.192)$. Higher satisfaction with the previous physician, shorter symptom duration, and increasing age were all associated with higher satisfaction after consultation ( $p<0.001, p=0.018, p<0.01$, respectively). Satisfaction with the previous physician was the strongest explanatory variable in the model.

\section{Discussion}

In a previous report it was shown that $62 \%$ of neurological SO or TR patients benefit from a day-care admission in terms of obtaining a new diagnosis or treatment proposal
[6]. The results of the present study show that in addition to those findings, a day-care admission for neurological SO patients and TR patients also enhances patients' satisfaction. Interestingly, patient satisfaction was not related to a new diagnosis or treatment advice, but rather to the amount of information and emotional support provided by the neurologist during the day-care admission. Probably the extra time available during a day-care admission compared to a regular outpatient clinic visit is of major importance for the satisfaction of the patients. The increase in overall satisfaction with the day-care clinic neurologist compared to the referring physician was significantly higher in SO patients compared to TR patients. This finding is not surprising, since SO patients initiated the day-care admission by themselves, whereas the TR patients did not request the day-care admission by themselves.

Previous studies in fields other than neurology also showed that lack of information, lack of emotional support, and poor communication are important motives of patients to seek additional consultation [8, 11-16].

The results of our study have important implications for neurological practice. Due to the limited amount of time available in regular outpatient clinics, physicians tend to spend most of the time focusing on diagnosis and treatment. We hypothesize that the extensive amount of time available is the most important factor leading to an increased satisfaction in the day-care clinic. Not only does the amount of time seem important, but this study has also shown that a substantial part of consultation time should be spent on informing the patient about the diagnosis and treatment as well as providing emotional support, as this appears equally important for the satisfaction of patients. Investing more time in the consultation itself as well as in communication and expressing empathy by physicians could help to reduce the number of expensive, time-consuming and sometimes unnecessary referrals to a tertiary care center. 
Table 3 Explanatory model for satisfaction after day-care consultation

\begin{tabular}{|c|c|c|c|c|}
\hline & \multicolumn{4}{|c|}{ Regression coefficients } \\
\hline & B1 & B2 & B3 $(95 \% \mathrm{CI})+\mathrm{SE} B$ & $p$ \\
\hline Age & 0.21 & 0.21 & $0.24(0.08 / 0.41)+0.18$ & $<0.01$ \\
\hline Gender & 2.75 & 2.85 & $2.48(-2.16 / 7.12)+0.06$ & 0.29 \\
\hline Education $^{\mathrm{a}}$ & -0.71 & -0.88 & $-0.96(-3.11 / 1.18)-0.05$ & 0.38 \\
\hline Number of physicians previously consulted & & -0.74 & $-0.76(-1.97 / 0.44)-0.08$ & 0.22 \\
\hline Symptom duration & & -0.05 & $-0.05(-0.09 /-0.01)-0.15$ & 0.02 \\
\hline Satisfaction previous physician & & 0.19 & $0.21(0.12 / 0.30)+0.29$ & $<0.001$ \\
\hline Referral type $\mathrm{b}^{\mathrm{b}}$ & & & $-5.91(-10.80 /-1.03)-0.15$ & 0.02 \\
\hline Constant & & & $62.84(47.84 / 77.84)$ & \\
\hline
\end{tabular}

Model fit: $R^{2}$ step B1: $0.034(F$-change $p=0.036), R^{2}$ step B2: $0.125(F$-change $p<0.001), R^{2}$ step B3: $0.145(F$-change $p=0.018), F: 5.879$ $p<0.001$

$S O$ second opinion, $T R$ tertiary referral, $C I$ confidence interval, $\mathrm{SE} \mathrm{B}=$ standardized regression coefficient

${ }^{\mathrm{a}}$ Education type, $1-2=$ low, $3=$ middle, $4-5=$ high

${ }^{\mathrm{b}}$ Referral type second opinion $=1$, tertiary referral $=2$

Only a small percentage of the variance of patient satisfaction could be explained using a model with a number of variables expected to influence satisfaction. Some variables which were expected to influence patient satisfaction, including the number of doctors previously consulted and referral type (SO vs. TR) did not explain or only marginally explained satisfaction. Apparently other, as yet unknown, factors play an important role in patient satisfaction. The fact that satisfaction with the previous physician was the strongest explanatory variable for satisfaction with the day-care admission suggests that personality traits could be a factor of importance. Some patients may be more difficult to satisfy, despite adequate consultation and communication skills of the physician. Few studies have investigated the relation between personality and patient satisfaction with care. Results suggest a marginal association between patients' scores on the dimension of agreeableness (mild, agreeable versus bossy, dominant) and satisfaction [17, 18].

The high response rate in our study and the inclusion of patients with general neurological problems lead to a high external validity of the results. However, results should be interpreted in view of some study limitations. First, the satisfaction questionnaire is primarily designed to assess patient satisfaction directly after the consultation. In this study, patients were asked to rate their satisfaction with the previous physician based on their recollection of this visit, possibly introducing recall-bias. Moreover, research suggests that satisfaction assessed immediately after the consultation mostly reflects communicative aspects of the interaction, whereas satisfaction assessed at a later point in time rather reflects improvement, or lack thereof, in patients' health [19]. Therefore, the lack of satisfaction with the previous physician could possibly partly be attributed to the lack of improvement of the medical condition, which is relatively often the case with neurological conditions, rather than the communication skills of the doctor. Finally, this study only investigated short-term satisfaction with the daycare admission.

Day-care admission for neurological SO and TR leads to an increase of patient satisfaction, irrespective of making a new diagnosis or initiation of a new treatment. Combining this study on satisfaction with our previous report that $62 \%$ of the patients in this cohort benefited in terms of a new diagnosis or treatment proposal [6], we conclude that a day-care admission is an effective way of evaluating neurological SOs and TRs. It remains to be determined which patients benefit most of such a day-care admission.

Acknowledgments No specific funding was obtained for this study.

Conflict of interest statement The authors declare that they have no conflict of interest.

Open Access This article is distributed under the terms of the Creative Commons Attribution Noncommercial License which permits any noncommercial use, distribution, and reproduction in any medium, provided the original author(s) and source are credited.

\section{References}

1. Sutherland LR, Verhoef MJ (1994) Why do patients seek a second opinion or alternative medicine? J Clin Gastroenterol 19:194-197

2. Cook IS, McCormick D, Poller DN (2001) Referrals for second opinion in surgical pathology: implications for management of cancer patients in the UK. Eur J Surg Oncol 27:589-594

3. Bekkelund SI, Salvesen R (2001) Are headache patients who initiate their referral to a neurologist satisfied with the 
consultation? A population study of 927 patients - the North Norway Headache Study (NNHS). Fam Pract 18:524-527

4. Bekkelund SI, Salvesen R (2002) Patient satisfaction with a neurological specialist consultation for headache. Scand J Prim Health Care 20:157-160

5. Hu XH, O’Donnell F, Kunkel RS, Gerard G, Markson LE, Berger ML (2000) Survey of migraineurs referred to headache specialists: care, satisfaction, and outcomes. Neurology 55:141-143

6. Wieske L, Wijers D, Richard E, Vergouwen MD, Stam J (2008) Second opinions and tertiary referrals in neurology: a prospective observational study. J Neurol 255:1743-1749

7. Blanchard CG, Labrecque MS, Ruckdeschel JC, Blanchard EB (1990) Physician behaviors, patient perceptions, and patient characteristics as predictors of satisfaction of hospitalized adult cancer patients. Cancer 65:186-192

8. Ong LM, Visser MR, Lammes FB, de Haes JC (2000) Doctorpatient communication and cancer patients' quality of life and satisfaction. Patient Educ Couns 41:145-156

9. Zandbelt LC, Smets EM, Oort FJ, Godfried MH, de Haes HC (2004) Satisfaction with the outpatient encounter: a comparison of patients' and physicians' views. J Gen Intern Med 19:10881095

10. Aalfs CM, Oort FJ, de Haes JC, Leschot NJ, Smets EM (2007) A comparison of counselee and counselor satisfaction in reproductive genetic counseling. Clin Genet 72:74-82

11. Frostholm L, Fink P, Oernboel E, Christensen KS, Toft T, Olesen F, Weinman J (2005) The uncertain consultation and patient satisfaction: the impact of patients' illness perceptions and a randomized controlled trial on the training of physicians' communication skills. Psychosom Med 67:897-905

12. Mellink WA, Dulmen AM, Wiggers T, Spreeuwenberg PM, Eggermont AM, Bensing JM (2003) Cancer patients seeking a second surgical opinion: results of a study on motives, needs, and expectations. J Clin Oncol 21:1492-1497

13. Ong LM, de Haes JC, Hoos AM, Lammes FB (1995) Doctorpatient communication: a review of the literature. Soc Sci Med 40:903-918

14. Saila T, Mattila E, Kaila M, Aalto P, Kaunonen M (2008) Measuring patient assessments of the quality of outpatient care: a systematic review. J Eval Clin Pract 14:148-154

15. Sutherland LR, Verhoef MJ (1989) Patients who seek a second opinion: are they different from the typical referral? J Clin Gastroenterol 11:308-313

16. van Dalen I, Groothoff J, Stewart R, Spreeuwenberg P, Groenewegen $P$, van Horn J (2001) Motives for seeking a second opinion in orthopaedic surgery. J Health Serv Res Policy 6:195-201

17. Finlay PM, Atkinson JM, Moos KF (1995) Orthognathic surgery: patient expectations; psychological profile and satisfaction with outcome. Br J Oral Maxillofac Surg 33:9-14

18. Hendriks AA, Smets EM, Vrielink MR, Van Es SQ, de Haes JC (2006) Is personality a determinant of patient satisfaction with hospital care? Int J Qual Health Care 18:152-158

19. Sutherland HJ, Lockwood GA, Minkin S, Tritchler DL, Till JE, Llewellyn-Thomas HA (1989) Measuring satisfaction with health care: a comparison of single with paired rating strategies. Soc Sci Med 28:53-58 